\title{
Student athletes claim to have more sexual partners than other students ${ }^{1}$
}

\author{
Charlotte Faurie ${ }^{\mathrm{a},}$, Dominique Pontier ${ }^{\mathrm{b}}$, Michel Raymond $^{\mathrm{a}}$ \\ a Génétique et Environnement, Institut des Sciences de l'Evolution de Montpellier (UMR CNRS 5554), Université \\ Montpellier II, II-CC 065, Place Eugène Bataillon F-34095 Montpellier cedex 05, France \\ b Biométrie, Génétique et Biologie des Populations (UMR CNRS 5558), Villeurbanne, France
}

* Corresponding author. Tel.: +33-4-67-14-46-32; fax: +33-4-67-14-36-22.
E-mail address: faurie@isem.univ-montp2.fr (C. Faurie).

\begin{abstract}
Physical competition is widespread in human societies. Because performance in competitive sports can signal phenotypic quality and fighting ability, high level performance, especially on the part of men, is likely to be attractive to the opposite sex. We investigated the relationship between involvement in competitive sport and self-reported numbers of sexual partners. Both male and female students who compete in sports reported significantly higher numbers of partners than other students, and within the athletes, higher levels of performance predicted more partners. Among men, body mass index (BMI) and educational level also had significant effects. We discuss possible implications for the evolution of competitive sport, ritual fighting behavior, and the persistence of left-handedness.
\end{abstract}

Keywords: Attractiveness; Fighting; Handedness; Sexual behavior; Polymorphism; Sexual selection; Sport

\footnotetext{
${ }^{1}$ This article was published in Evolution and Human Behavior (25) Faurie, C., Pontier, D., Raymond M., Student athletes claim to have more sexual partners than other students, Pages 1-8, (C) 2004, and is posted with permission from Elsevier. EVOLUTION AND HUMAN BEHAVIOR Home Page:

http://www.elsevier.com/wps/find/journaldescription.cws_home/505760/description\#description
} 


\section{Introduction}

Physical competition is ubiquitous in human societies (e.g., Chick \& Loy, 2001). In particular, ritualized fights occur in many cultures, and often advertise fighting ability (e.g., the chest pounding duels of the Yanomamo" ; Chagnon, 1997). In modern societies, sports may act as a proxy for fighting ability because they demand good visual-spatial judgement, speed, endurance, and strength (Manning \& Taylor, 2001). The level that one attains in sporting competitions is thus an honest signal of general body condition and other aspects of phenotypic quality. Interactive sports, such as boxing, judo, fencing, and even tennis, can be considered rule-bound ritual fights in which severe wounds and death are forbidden, and they convey information about capabilities in real fights (Raymond, Pontier, Dufour, \& Møller, 1996). Thus, involvement in sports may be interpreted in the context of sexual selection, i.e., mate choice and competition for access to mates.

The present study was performed to assess the relationship between the level achieved in sporting competition and the number of opposite-sex sexual partners. At least for males, this number was an important component of expected fitness in past environments (Pérusse, 1993), and in both sexes, the number of partners is correlated with attractiveness (Taylor \& Glenn, 1976; for reviews, see Buss, 1999; Cartwright, 2000). One who has had many partners has been repeatedly accepted or chosen, and can be considered, ipso facto, relatively attractive; moreover, since more attractive people have more options and access to mates of higher quality, the number of sexual partners may be an indicator of expected fitness in both sexes. We predicted that sports competitors should have more sexual partners than other people, that numbers of partners should increase with performance level, and that these effects should be more pronounced in males than in females.

\section{Methods}

An anonymous questionnaire was given to 605 French students from three universities (Montpellier, Lyon, and Bordeaux), who were either registered for "physical and sportive activities" as preparation for becoming sports teachers and involved in high level competitive sport (SP), or registered for biological sciences and not involved in competitive sport (non-SP). Participants provided information on their age, sex, body mass, height, degree program and level, and number of sexual partners of the opposite sex during the past year. (Self-reports of height and weight are often viewed with scepticism, but there is evidence that people report their body weights and heights with surprising accuracy; see Palta, Prineas, Berman, \& Hannan, 1982; Stundkard \& Albaum, 1981.) We computed each subject's body mass index: BMI $=$ mass $/(\text { height })^{2}$, which has been shown to be a better predictor of bodily attractiveness than other measures of weight, height, and body shape (Tovée, Reinhardt, Emery, \& Cornelissen, 1998). The SP subjects also reported what level of sporting competition they had attained on a five-level ordinal scale: departmental, regional, interregional, national, or international.

Because of skewed distributions, nonparametric tests were used to compare numbers of partners between men and women, and between groups SP and non-SP. BMI was compared between groups SP and non-SP by analysis of variance. These analyses were performed using JMP IN 3.2.1 software (SAS Institute Inc., Cary, NC). Data were further analysed by logistic regression, testing for effects on partner number of sex, age, BMI, SP versus non-SP, and academic year, plus all possible second and third order interactions; model simplification was then conducted via backward elimination, following Crawley (1993). These analyses were performed separately for men and women, because all third order interactions involving sex of respondent were significant. Then we analysed separately the group SP to test for an additive effect of the level achieved in sporting competition. Models were fitted using GLIM software (Baker, 1987).

\section{Results}

Out of 605 returned questionnaires, 527 were complete and included in the study (87.1\%): 167 SP women, 250 SP men, 60 non-SP women, and 50 non-SP men. Ages ranged from 17 to 29, 
and did not differ between the sexes: mean \pm S.D. $=20.2 \pm 1.4$ years for women, $20.3 \pm 1.5$ for men $[\mathrm{F}(1,525)=1.4 ; P=.24]$. Mean age did differ between the SP group $(20.1 \pm 0.1)$ and the non-SP group $[20.8 \pm 0.2 ; \mathrm{F}(1,525)=19.0 ; P<.0001]$, but this is taken into account with the GLM modelling.

\subsection{Reported number of sexual partners}

Distributions of reported numbers of partners in the past year are portrayed in Fig. 1. Within both sexes, non-SP respondents were relatively likely to report one partner, or none, and SP respondents were relatively likely to report multiple partners. On average, SP males reported $2.41 \pm$ 0.20 partners and non-SP males $1.24 \pm 0.22$; SP females reported $1.60 \pm 0.14$ and non-SP females $1.12 \pm 0.11$. The SP/non-SP difference was significant for both sexes (Wilcoxon test: $z=-4.25, P<$ .0001 for men; $z=-2.23, P=.02$ for women). The sex difference was significant within the SP group $(\mathrm{z}=-3.13, P=.002)$, but not within the non-SP group $(\mathrm{z}=-0.85, P=.4)$.

(a)

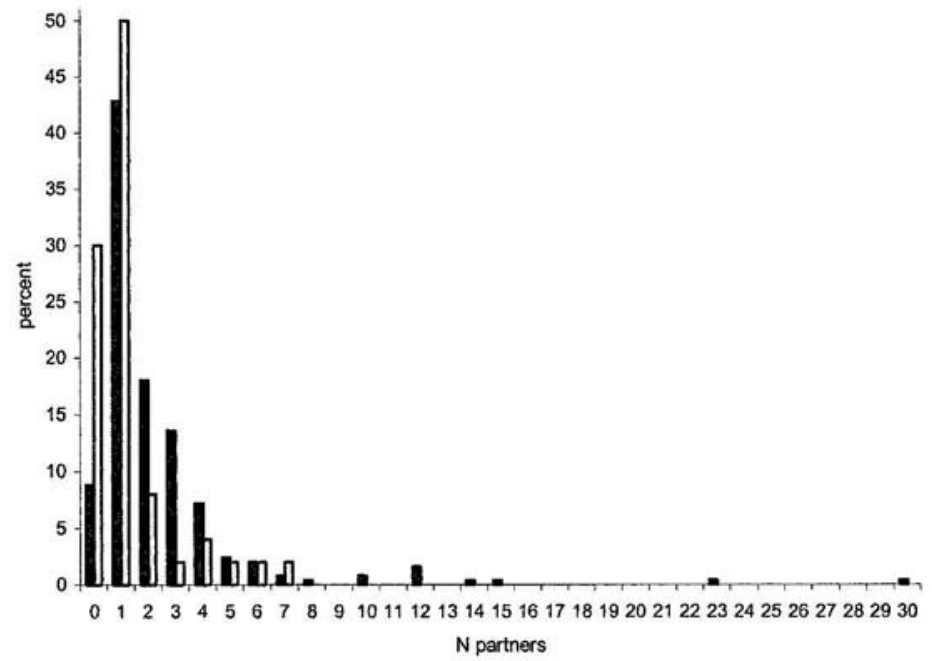

(b)

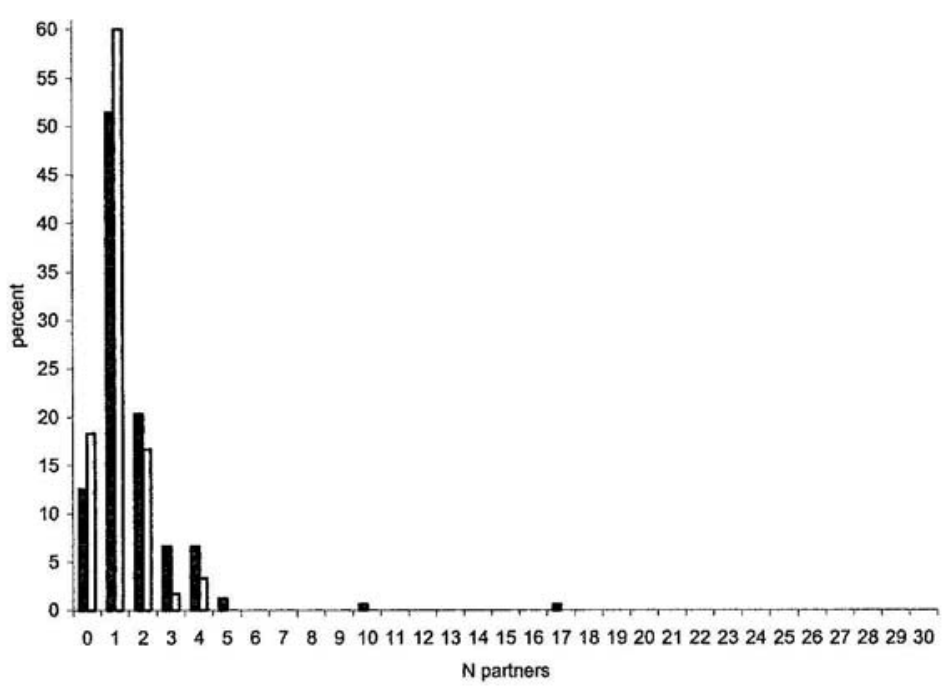

Fig. 1. Distribution of the reported number of sexual partners of the sport students (SP, dark bars) and non-SP students (non-SP, open bars): (a) men, (b) women.

(C) Elsevier Inc. All rights reserved. 


\subsection{BMI comparisons}

Mean BMI was $23.1 \pm 0.1$ for SP men and $21.6 \pm 0.3$ for non-SP men, a significant difference $[\mathrm{F}(1,303)=23.7, P<.00001]$. This difference was smaller, but still significant, in women: SP $20.8 \pm 0.1$, non-SP $20.2 \pm 0.2[\mathrm{~F}(1,238)=3.0, P=.015]$.

\subsection{Models best explaining the number of sexual partners}

Logistic regression was used for simultaneous assessment of the effects of age, BMI, educational level, and group (SP vs. non-SP) on the reported number of sexual partners, within each sex considered separately.

For women, SP versus non-SP group was the significant predictor $\left(\chi^{2}\right.$ test: $\left.P=.003\right)$, with SP women reporting more partners.

For men, the minimal model included group, BMI, educational level, and the group $\times$ BMI interaction (Table 1). Because the second to fourth levels did not have significantly different effects, the four educational levels were reduced to two: low level (1st year of university studies, value 1) and high level (2nd to 4th year, value 2). Within each group (SP and non-SP, respectively), 1st year students reported more sexual partners than higher level students $(P=.0002)$. Because the group $\times$ BMI interaction had a significant effect $(P=.007)$, it could not be removed from the model, and separate $\chi^{2}$ tests could not be performed for these two variables. However, the linear estimate of the change in intercept for non-SP students (compared to SP students) is more than 2.8 times larger than the corresponding standard error, suggesting a substantial and significant effect of the group, when controlling for all other variables. For a given educational level, the number of sexual partners predicted by the model is always larger for the SP students than for the non-SP students.

Table 1

Variables explaining the number of sexual partners in the minimum adequate model (GLM), linear estimates, and standard error

\begin{tabular}{lllll}
\hline & Variable & Linear estimate & S.E. & Term \\
\hline Men & EDU(1), SP & +0.303 & 0.472 & Intercept for group SP and low educ. level \\
& BMI & +0.024 & 0.020 & Slope for group SP and low educ. level \\
& non-SP & -3.842 & 1.341 & Change in intercept for group non-SP \\
& EDU(2) & -0.483 & 0.137 & Change in intercept for high educ. level \\
& non-SP $\times$ BMI & +0.158 & 0.058 & Change in slope for group non-SP \\
\multirow{4}{*}{ Women } & SP & +0.490 & 0.062 & Intercept for group SP \\
& non-SP & -0.442 & 0.140 & Change in intercept for group non-SP \\
\hline
\end{tabular}

EDU (education level: values 1,2) and group (values SP, non-SP) are qualitative variables i.e., factors, and BMI is a quantitative variable. The last column details the significance of each linear estimate in the model (for qualitative variables, linear estimates give the intercept or change in intercept of the regression line, and for quantitative variables they give the slope or change in slope).

From this table, one can deduce the equation of the regression line for the value of all factors. For example: for group SP and low educational level, the line describing $\ln$ (number of sexual partners) as a function of BMI has an intercept of 0.303 and a slope of 0.024 ; for group non-SP and low educational level, the intercept is -3.539 $(=0.303-3.842)$ and the slope is $0.182(=0.024+0.158)$; etc.

(C) Elsevier Inc. All rights reserved.

Because age and education level were highly correlated (Kendall's $\tau=0.35, P<.0001$ ), they were introduced in the model together and separately. Model selection was performed using the Akaike Information Criterion (AIC), a heuristic measure that can be compared between unrelated models fitted on the same data (AIC $=$ deviance $+2 d f$ ) (Akaike, 1974). Education level turned out to be a better explanatory variable than age in the model for males, as the AIC was minimum (with education: AIC $=498.41$; with age: AIC $=511.07)$. In the model for females, none of these variables had a significant effect, even when introduced separately. 


\subsection{Effect of level achieved in sporting competition on the number of sexual partners}

Within the group SP, the level achieved in competition had a further effect on the reported number of sexual partners beyond the effects of all other explanatory variables. The five levels of competition had to be grouped into two significantly different ones: low level (departmental or regional competitions) and high level (interregional, national, or international competitions). Among men, high-level competitors reported $2.43 \pm 0.20$ sexual partners during the past year versus $2.11 \pm$ 0.23 for low-level competitors $(P=.03$ by Wilcoxon test). Among women, high-level competitors reported $1.82 \pm 0.19$ partners versus $1.47 \pm 0.20$ for low-level competitors $(P=.003)$.

\section{Discussion}

As predicted, competitive athletes of both sexes reported significantly more sexual partners than other students, and this effect was larger in men than in women.

The difference in BMI between the two groups, probably due to the muscular mass of sports competitors, suggests a different morphology which may translate into greater attractiveness, but the differences in numbers of sexual partners need not reflect differences in attractiveness. For example, the groups may differ in opportunities: high-level sport entails much travel for competitions, training internships, etc., perhaps increasing one's chances to meet potential partners. The fact that student athletes have more sexual partners and more muscle mass may be due to their intense training, i.e., to the fact that they have devoted their time to sport, while the other students devoted their time to other academic pursuits, and the results could also reflect differences in sexual motivation or personality between the two students groups rather than a difference due to athleticism. But whatever the proximate explanation may be, the results clearly indicate that SP students surpass the non-SP comparison group in their access to mates.

Even within the student athletes, the level achieved in competition predicted the number of partners, perhaps because the prestige enjoyed by high-level athletes enhances their attractiveness, although other factors such as travel-based opportunity may again be relevant. Men in their 1st year of university reported more partners within the past year than those in their 2 nd to 4th years. This may seem surprising in light of Michael, Gagnon, Laumann, and Kolata's (1994) finding that education level is a positive predictor of partner number in a large sample of individuals aged 18 to 59, and in light of the fact that attractiveness and social status are positively related (Buss, 1999). However, this difference probably reflects aspects of student life. First year students are especially likely to have changed homes and social groups within the preceding year, and investment in studying (and future social status) may increase with the level of study, requiring a reduction in mating effort.

These findings must be interpreted with caution. As in other studies, we found that men reported more partners than did women. Morris (1993) showed that this discrepancy does not decrease when the sample size increases, and that it is mostly due to individuals reporting a high number of partners $(>20)$, suggesting that these individuals give imprecise answers, with men tending to overstate and/or women to understate their number of partners. Even allowing for age differences in the selection of partners by males and females, the most powerful factor appears to be female understatement (Baker \& Bellis, 1995). Brewer et al. (2000) showed that female prostitutes are usually underrepresented in the samples of such studies, and that the discrepancy is reduced when they are included, but it seems unlikely that the use of prostitutes explains the differences that we observed.

Left-handers are known to be overrepresented among people practicing interactive sports, because they have a frequency-dependent advantage (Grouios, Tsorbatzoudis, Alexandris, \& Barkoukis, 2000; Raymond et al., 1996). For example, in Western societies, the frequency of lefthanders, which is about 10\% overall, reaches $44.5 \%$ among fencing champions (Raymond et al., 1996). Handedness is polymorphic in all human populations with lefthandedness always in the minority (see Raymond \& Pontier, 2004, for a review); moreover, handedness is substantially heritable (see, e.g., Francks et al., 2002; McKeever, 2000; McManus, 1991; Sicotte, Woods, \& Mazziotta, 1999). Why left-handedness persists has been a puzzle because of evidence of associated 
fitness costs (e.g., Aggleton, Kentridge, \& Neave, 1993; Coren \& Halpern, 1991; Gangestad \& Yeo, 1997; McManus \& Bryden, 1991). It would seem that some countervailing benefit, probably frequency-dependent, is required to maintain the polymorphism, and the results of our study suggest that in light of the disproportionate prevalence of left-handers among athletes, that benefit may reside, at least in part, in the sexual success of athletes.

We also found that sports students competing at a high level reported more sexual partners than individuals competing at a low level. This fact suggests that it will be valuable to extend the present study to sporting individuals competing at higher levels, as well as to other age groups and other societies. Ritual fights and competition on physical aptitudes exist in many other societies and could have an effect on social status and attractiveness, as suggested by Hill (1984) and Chagnon (1988). Finally, our hypothesis that left-handers enjoy a mating advantage that offsets disadvantages in survival and other domains requires direct testing.

\section{Acknowledgments}

We thank S. Billiard, S. Brown, G. Kunstler, H. Leturque, A. P. Møller, and F. Rousset for their helpful advice and comments, C. Berticat, V. Bouchaud and L. Courtel for their help in distributing questionnaires, two anonymous reviewers and Martin Daly for constructive criticism and several valuable suggestions, and all participants for their interest. This is contribution 2003.054 of the Institut des Sciences de l'Evolution de Montpellier (UMR CNRS 5554).

\section{References}

Aggleton, J. P., Kentridge, R. W., \& Neave, N. J. (1993). Evidence for longevity differences between left handed and right handed men: an archival study of cricketers. Journal of Epidemiology and Community Health, 47, 206-209.

Akaike, H. (1974). A new look at the statistical model identification. Institute of Electrical and Electronics Engineers Transactions on Automatic Control, 19, 716-723.

Baker, R. J. (1987). GLIM 3.77 reference manual. Oxford, UK: Numerical Algorithms Group.

Baker, R. R., \& Bellis, M. A. (1995). Human sperm competition. Copulation, masturbation and infidelity. London: Chapman \& Hall.

Brewer, D. D., Potterat, J. J., Garrett, S. B., Muth, S. Q., Roberts, J. M., Kasprzyk, D., Montano, D. E., \& Darrow, W. W. (2000). Prostitution and the sex discrepancy in reported number of sexual partners. Proceedings of the National Academy of Sciences of the United States of America, 97, 12385-12388.

Buss, D. M. (1999). Evolutionary psychology, the new science of the mind. Boston: Allyn and Bacon.

Cartwright, J. (2000). Evolution and human behavior: Darwinian perspectives on human nature. Cambridge, MA: MIT Press.

Chagnon, N. A. (1988). Life histories, blood revenge, and warfare in a tribal population. Science, 239, 985-992.

Chagnon, N. A. (1997). Yanomamo". New York: Harcourt Brace College Publishers.

Chick, G., \& Loy, J. W. (2001). Making men of them: male socialization for warfare and combative sports. World Cultures, $12,2-17$.

Coren, S., \& Halpern, D. F. (1991). Left-handedness: a marker for decreased survival fitness. Psychological Bulletin, 109, 90-106.

Crawley, M. J. (1993). GLIM for ecologists. Oxford, UK: Blackwell.

Francks, C., Fisher, S. E., MacPhie, I. L., Richardson, A. J., Marlow, A. J., Stein, J. F., \& Monaco, A. P. (2002). A genome wide linkage screen for relative hand skill in sibling pairs. American Journal of Human Genetics, 70, 800-805.

Gangestad, S. W., \& Yeo, R. A. (1997). Behavioral genetic variation, adaptation and maladaptation: an evolutionary perspective. Trends in Cognitive Sciences, 1, 103-108.

Grouios, G., Tsorbatzoudis, H., Alexandris, K., \& Barkoukis, V. (2000). Do left-handed competitors have an innate superiority in sports? Perceptual and Motor Skills, 90, 1273-1282.

Hill, J. (1984). Prestige and reproductive success in man. Ethology and Sociobiology, 5, 77-95.

Manning, J. T., \& Taylor, R. P. (2001). Second to fourth digit ratio and male ability in sport: implications for sexual selection in humans. Evolution and Human Behavior, 22, 61-69.

McKeever, W. F. (2000). A new family handedness sample with findings consistent with X-linked transmission. British Journal of Psychology, 91, 21-39.

McManus, I. C. (1991). The inheritance of left-handedness. In: G. R. Bock, \& J. Marsh (Eds.), Biological asymmetry and handedness, Ciba Foundation Symposium (pp. 251-281). London: Wiley.

McManus, I. C., \& Bryden, M. P. (1991). Geschwind's theory of cerebral lateralization: developing a formal, causal model. Psychological Bulletin, 110, 237-253. 
Michael, R. T., Gagnon, J. H., Laumann, E. O., \& Kolata, G. (1994). Sex in America. A definitive survey. New York: Little Brown.

Morris, M. (1993). Telling tales explains the discrepancy in sexual partner reports. Nature, 365, 437-440.

Palta, M., Prineas, R. J., Berman, R., \& Hannan, P. (1982). Comparison of self-reported and measured height and weight. American Journal of Epidemiology, 115, 223-230.

Pérusse, D. (1993). Cultural and reproductive success in industrial societies: testing the relationship at the proximate and ultimate levels. Behavioral and Brain Sciences, 16, 267-322.

Raymond, M., \& Pontier, D. (2004). Is there a geographical variation of human handedness? Laterality, 9 (in press).

Raymond, M., Pontier, D., Dufour, A.-B., \& Møller, A. P. (1996). Frequency-dependent maintenance of left-handedness in humans. Proceedings of the Royal Society of London B, 263, 1627-1633.

Sicotte, N. L., Woods, R. P., \& Mazziotta, J. P. (1999). Handedness in twins: a meta-analysis. Laterality, 4, $265-286$.

Stundkard, A. J., \& Albaum, J. M. (1981). The accuracy of self-reported weights. American Journal of Clinical Nutrition, 34 , 1593-1599.

Taylor, P. A., \& Glenn, N. D. (1976). The utility of education and attractiveness for females status attainment through marriage. American Sociological Review, 41, 484-498.

Tovée, P. J., Reinhardt, S., Emery, J. L., \& Cornelissen, P. L. (1998). Optimum body-mass index and maximum sexual attractiveness. Lancet, 352, 548. 